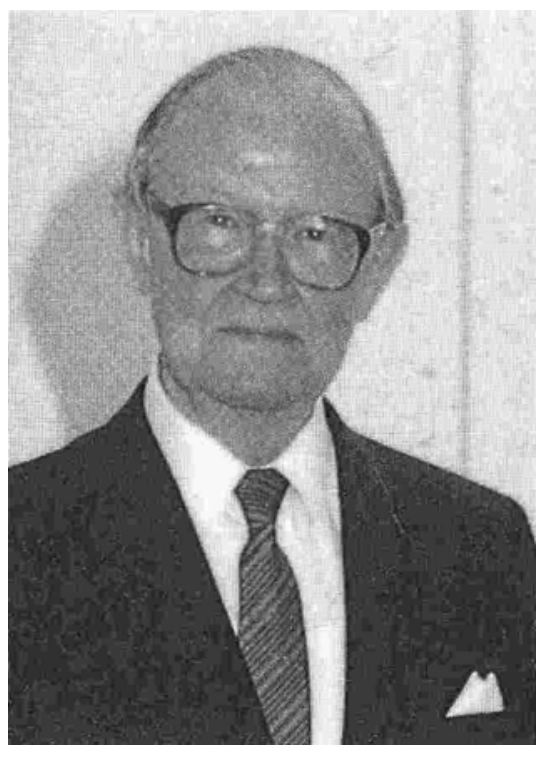

\title{
Professor Dr.-Ing. Dr. h. c. Franz Kollmann $\dagger$
}

Am 17. September 1987 verstarb der Begründer und langjährige Herausgeber dieser Zeitschrift, Professor Dr.-Ing. Dr.h.c. Franz Kollmann, kurz vor der Vollendung seines 81. Lebensjahres.

Mit Franz Kollmann endet eine entscheidende Ära der Holzforschung, denn er war der erste Forscher, der die Wissenschaft vom Holz umfassend verstanden und betrieben hat. Er war es, der Holzforschung als interdisziplinäre Aufgabe sah und konsequent verwirklichte.

Seine unersetzlichen Standardwerke über die Technologie des Holzes und der Holzwerkstoffe, die von ihm begründeten, international verbreiteten Fachzeitschriften und die von ihm initiierte Internationale Akademie der Holzwissenschaften haben dieser umfassenden Idee einer Holzforschung zum Durchbruch verholfen.

Die Verdienste, die sich Franz Kollmann für die Holzforschung sowie für die Forst- und Holzwirtschaft erworben hat, sind unvergeßlich. Sein Wirken lebt in dem von ihm gegründeten Institut für Holzforschung in München fort, das Wissenschaftler der verschiedensten Fachrichtungen zusammenführt und ihnen ermöglicht, Holzforschung im breitesten Kollmannschen - Sinne zu betreiben.

Wir trauern um Franz Kollmann.

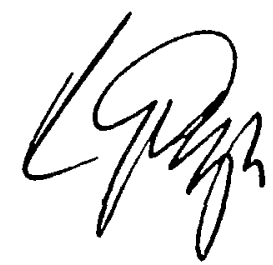

Dr. H. Götze Springer-Verlag

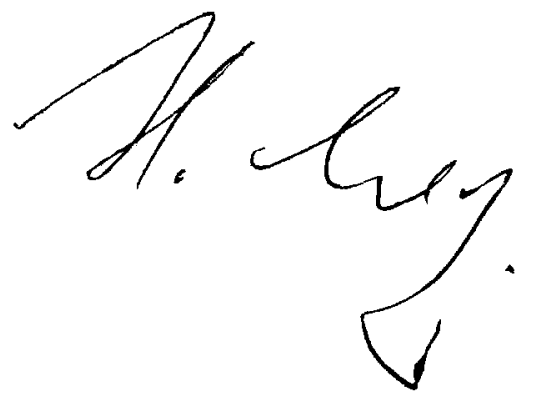

Professor Dr. H. Schulz

Herausgeber und Vorstand des Instituts für Holzforschung der Universität München
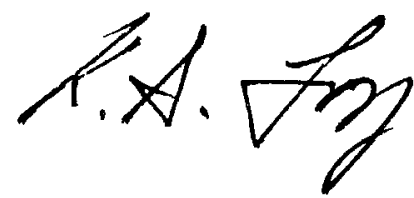

Dipl.-Ing. K.-A. Sorg Schriftleiter

Leben und Werk von Prof. Kollmann wurden in dieser Zeitschrift in den Heften 10/66, 9/71, 9/74, 10/76, 8/77, 10/81 und 10/86 gewürdigt. Seine Veröffentlichungen sind dort verzeichnet. 1987 sind aus seiner Feder erschienen:

Poren und Porigkejt in Hölzern. Holz als Roh- und Werkstoff 45 (1987): 1-9

Beiträge zur Holzphysik. Holz-Zbl. 113 (1987):318-320

Holzwissenschaft weltweit auf dem Vormarsch. Holz-Zbl, 113 (1987): 720

Übersicht über wichtige Nutzhölzer. Holz-Zbl. 113 (1987):860-862

Renaissance des Holzes (1): Holz in der Waldwirtschaft - Verfügbarkeit und Bedarf; (2): Die Zukunft des Holzes ist gesichert.

Holz-Zbl. 113 (1987): 1060-1062; 1138 